2. To confirm the possibility of its removal once it has been located.

3. To record that full recovery of vision is possible after removal.

\title{
REFERENCES
}

1. Brit. Jl. Ophthal., Annotation, April, 1941.

2. Bickerton.-Brit. Med. Jl., Vol. I, 1888.

3. Claiborne.-Amer. Jl. of Surgery, Vol. XXXVI, 1922.

4. BURKe.-Trans. Amer. Ophthal. Soc., Vol. XXVIII, pp. 53-60, 1930.

\section{THE AETIOLOGY OF AN OBSCURE CASE OF RETROBULBAR NEURITIS}

BY

\author{
ROSA FORD \\ LONDON
}

WE still see a number of cases of retrobulbar neuritis the cause of which is obscure. Carroll, ${ }^{1}$ in 1940 , went through 100 of his cases and found the cause undetermined in no fewer than 34 .

When we have excluded trauma and tumour, the Wassermann reaction is negative, and a negative report is received from an investigation of the para-nasal sinuses, we are left with the suspicion that the condition may be the first symptom of disseminated sclerosis. As we do not know the cause of this either, the position is an unsatisfactory one.

The case here described was at first in this unexplained category, but later events cleared the diagnosis, so that a report may help to throw light on other obscure cases.

A.E., a woman aged 31 years, was first seen in April, 1930, because for 2 months she had been unable to do the fine needlework at which, till then, she had been particularly good. Vision was $6 / 18$ in each eye and the fundi were normal.

In the search for a cause, every investigation, medical, dental (with X-ray), rhinological (with X-ray) and the Wassermann reaction proved negative. During the next few months her sight varied, occasionally becoming $6 / 9$, but in July it was still only $6 / 18$ in both eyes.

Seven months from the onset, it was decided to explore the sphenoidal sinuses, and thick pus was withdrawn from the left and cloudy mucus from the right. Recovery followed when both spheno-ethmoidal sinuses were opened, but this was speedily 
followed by a relapse, which again yielded to a wider opening of the same sinuses. Then came a long series of relapses and recoveries, and attempts to maintain nasal drainage grew less and less successful. Finally, in 1935, the antra were opened and found to be full of pus.

After double antrostomy, she left the downgrade path for the upgrade, and now, in 1941, has for some years been again an excellent needlewoman.

The reason why this patient had remained for 7 months in the category of unexplained cases of retrobulbar neuritis was because she had a normal nose. Two well-known rhinologists had examined her, the one at 2 months, the other at 5 months from the onset, and both agreed, that in bony conformation and appearance of the mucous membrane, the nose was remarkably normal and without the slightest suspicion of any underlying sinusitis.

There was moreover no catarrh nor any history of such.

The X-ray report only queried the left frontal sinus.

The subsequent findings in this case, therefore, justify the following conclusions :-

1. Sinus disease can exist when the nose appears to be perfectly normal clinically, and when there is no definite radiological evidence of its presence.

2. Sinus disease can exist when there is no catarrh nor any history of such.

3. Retrobulbar neuritis may be a symptom of this concealed sinus disease.

These conclusions may be helpful to an ophthalmologist confronted with a similarly obscure case. With every other possible cause excluded, he will have sought an opinion from a rhinologist, because he knows that some cases of retrobulbar neuritis have been due to sinus disease. With a negative report, however, he is obliged to rule out sinus disease, especially as in 1940 Duke-Elder ${ }^{4}$ summed up present ophthalmic opinion in these words, "the sinuses of every case of retrobulbar neuritis should be investigated, but the evidence points to the conclusion that intra-nasal surgery should not be resorted to lightly except in progressive cases, in the presence of obvious sinus disease, (the italics are mine) and in the absence of other aetiological factors."

With no further avenue for search, the ophthalmologist is obliged to adopt a waiting policy, in the hope that the condition will clear in time as it often does, at least partially. In these circumstances he is quite justified in this policy, as is also the rhinologist in his negative report.

The present case, however, gives some indication that the reception of a negative rhinological report in a case of retrobulbar 
neuritis does not end ophthalmic responsibility. Both signs and symptoms are ophthalmic, and it is thus the ophthalmic surgeon alone who can request further investigation from a rhinologist, in whose sphere there is neither sign nor symptom.

If he is to do this, he will wish to be sure of his grounds.

In this case, the ophthalmic surgeon's diagnosis of sinus disease was based on two considerations :-

1. The History.-The visual defect followed a bad cold and was accompanied by double ptosis, marked photophobia, severe headache and "terrible head noises." In addition to these more local symptoms, there was evidence of toxaemia in the marked insomnia and loss of appetite and weight, and this formerly remarkably healthy woman had " no life" in her.

The toxaemia suggested septic absorption, and the onset with a cold, together with the head and visual symptoms, indicated a location of the sepsis in the sinuses.

2. The Fields.-With the perimeter, using an $8 \mathrm{~mm}$. white object, these showed marked contraction. Giving the nearest and farthest distances from the fixation point, these were R.E. $30^{\circ}$ to $50^{\circ}$, L.E. $20^{\circ}$ to $40^{\circ}$.

With the scotometer, using a $1 \mathrm{~mm}$. white object at 2 metres, this contraction was seen to approach the fixation point above, in the R.E. to $6^{\circ}$ and in the L.E. to $2^{\circ}$.

This contraction, invading the central area, explains the defect in central vision.

Such fields have often been reported as the result of sinus disease, e.g., by D. Stenhouse Stewart ${ }^{3}$ who depicted the fields before and after nasal drainage, and in the case A.S., reported ${ }^{2}$ by me, in which the field-charts before and after nasal drainage are reproduced.

Confirmation of this diagnosis was obtained when pus was found in the sphenoidal sinus, but during the next five years before the antral disease was discovered, the patient's failure to complete her recovery seemed unaccountable. Her restored sight after the spheno-ethmoidal operations, showed that the cause of the retrobulbar neuritis was sinus disease, but the constant relapses, in spite of every effort to maintain drainage, was mysterious and pointed to some possible second factor, perhaps the same that was responsible for some of Carroll's 34 per cent. of unexplained cases.

Now that we know it was no mystery, but simply the block caused by the diseased antra, it becomes very important to the ophthalmologist to realise that even after five years, the antral disease was not obvious to the rhinologist.

A third rhinologist investigated the antra at my request in 
January, 1935, punctured and irrigated them and saw a few flakes of mucus in the washings but did not advise further action. The following December, again at my request, antrostomy cleared the diagnosis and made recovery possible.

It is eleven years since the first happenings in this case, and later experience has brought increased confidence in the diagnosis of sinus disease by the history and fields, without the necessity for the suction-exploration employed in this case.

Confirmation is obtained when nasal drainage leads to recovery. In this case, during the pre-operative 7 months, much relief was obtained by intra-nasal medication with argyrol and glycerine, and vision improved markedly, especially after a considerable discharge of mucus from the nose, though this improvement only continued intermittently. Headaches remained severe and constant, and she was " always tired."

Had the antra been opened at that time instead of the posterior sinuses, it seems probable that no further surgery might have been required and that this long illness would have been prevented.

Intra-nasal medication, supplemented, if necessary, by double antrostomy, may thus give sufficient confirmation of the original diagnosis without recourse to exploration.

\section{Summary}

A case of retrobulbar neuritis was diagnosed by the ophthalmologist, from the history and fields, as due to sinusitis.

Confirmation by the rhinologist was delayed 7 months because neither sign nor symptom of sinusitis was present. It was then obtained by exploratory puncture of the sphenoids, and the withdrawal of pus from the left, and cloudy mucus from the right.

Though the spheno-ethmoidal sinuses were opened, recovery was only partial for 5 years until the apparently normal antra were also opened and found to be full of pus.

\section{Conclusion}

In any case of retrobulbar neuritis in which the cause is obscure, the possibility of concealed sinusitis should be considered. A preliminary diagnosis can be made by the ophthalmic surgeon from the history and fields. Should a subsequent negative rhinological report be received, this does not end ophthalmic responsibility, for it is the ophthalmic surgeon alone who can request further investigation from a rhinologist who, on his own findings, sees no reason for it.

Suction-exploration, when carried out by the method taught by Watson Williams, can give a decisive diagnosis. 
Intra-nasal medication, supplemented, if necessary, by double antrostomy, may give sufficient confirmation, by the patient's recovery, without the necessity for exploration.

\section{REFERENCES}

1. Carroll, F. D.-Arch. of Ophthal., Vol. XXIV, p. 54, July, 1940.

2. Ford, Rosa.-Proc. Roy. Soc. Med., Vol. XXIV (Sect. Ophthal.), pp. 35-40, May, 1931.

3. Stewart, D. Stenhouse.-Brit. Jl. Ophthal, Vol. XII, p. 413, 1928.

4. Duke-Elder, Sir STEWart.-Text-book of Ophthal., Vol. III, p. 2988.

THE TONIC PUPIL SYNDROME

BY

Percival W. Leathart

LIVERPOOL

IN 1924 and later in 1931 Foster Moore described this syndrome calling it "non luetic Argyll Robertson pupil." In 1931 Holmes described it under the name "partial iridoplegia." In 1931-32 Adie described it, introducing the term "tonic pupil." In their papers these pioneers do not suggest a lesion capable of producing the physical signs of the syndrome they describe. This paper is an attempt to do so.

The syndrome is recognised by three physical signs each of which points to some interference with the nervous mechanism of the internal muscles of the eye.

1. The pupillary reaction to light is absent or sluggish.

2. The affected pupil is larger than its fellow but will dilate further in the dark, and to atropine.

3. The pupillary reaction to convergence is slower than normal in spite of the fact that near vision is unaffected. The rest of the eye is normal in all respects. There is no external muscular paresis, no ptosis or nystagmus and no en- or exophthalmos. In a certain number of cases the knee jerks and ankle jerks are absent or reduced. The syndrome is commoner in women.

Before entering into a discussion with regard to the location of a lesion capable of producing the above physical signs, it is necessary to describe in some detail the anatomy of the primary ocular reflexes concerned. In this description reference to decussations is omitted for the sake of simplicity.

Rough diagrams are appended in order to make the descriptions less confusing. 